\title{
THE DISTRIBUTION OF THE ABH SECRETORS WITH MYOTONIC DYSTROPHY IN SAN-IN DISTRICT OF JAPAN
}

\author{
Kaoru Tanaka, ${ }^{1}$ Kenzo TaKeshita, ${ }^{1}$ and Toshio NaKashima ${ }^{2}$ \\ ${ }^{1}$ Brain Research Institute, Division of Child Neurology, Tottori University \\ School of Medicine, Yonago, Tottori 683, Japan \\ ${ }^{2}$ Matsue National Hospital, Matsue, Shimane 690, Japan
}

\begin{abstract}
Summary The prevalence rate of myotonic dystrophy in San-in district of Japan was approximately $1: 46,000$. The blood groups of 25 subjects, including 14 patients and 11 healthy relatives, were surveyed, which failed to present the maldistribution of secretors and non-secretors. The genetic linkage between the locus for myotonic dystrophy and the $\mathrm{ABH}$-secretion locus was seen equilibrated. Some of the families permitted prenatal prediction.
\end{abstract}

\section{INTRODUCTION}

The locus of myotonic dystrophy gene is linked with the secretor gene (Renwick et al., 1971). The genetic map distance of these loci is 8 centimorgans (Renwick et al., 1971) or 11 centimorgans (Harper et al., 1972) without sex difference. Linkage of marker characters with hereditary diseases provides means for establishing prognosis and genetic counselling (Nei, 1979), that can at the same time be applied to establishment of prenatal prediction in view of the possibility of the secretor state of a young fetus being determined from the amniotic fluid (Harper et al., 1971).

The blood group of secretory and non-secretory types of 25 subjects from 6 families including 14 patients in San-in district of Japan was surveyed for the following purposes; (1) to study the possibility of establishing the prenatal prediction and preclinical detection from genealogy, (2) to investigate whether or not the distribution of secretory and non-secretory blood groups differ between the patients' population and a general population, and (3) to investigate the difference in the distribution of secretory and non-secretory blood groups between children from an affected spouse and children from the normal parents.

Received February 24, 1981

* This study was supported by a grant-in aid (1980) for neurological disease by the Ministry of Health and Welfare of Japan. 


\section{METHOD}

The ABO blood group was determined in accordance with the directions of anti-A and B sera. The ABH blood substance in the saliva was examined by inhibition of hemagglutination according to the microtiter technique. The verification of secretory and non-secretory typing was achieved by blood grouping of Lewis type (Grubb, 1948) using anti-Le ${ }^{a}$ and $\mathrm{Le}^{\mathrm{b}}$ sera (Ortho Diagnostics, Inc., N.J.).

\section{RESULTS}

The prevalence rate of patients with myotonic dystrophy observed from January, 1974 to May, 1980 in San-in district of Japan was approximately $1: 46,000$. The analytical survey of blood group of 25 subjects, including 14 patients and 11 healthy relatives, was carried out.

(1) The pedigree as observed in the present study is illustrated together with the ABO type (upper) and secretory blood type (lower) of those whose blood was tested (Fig. 1). The pedigree data were completed with conjugal blood types in 6 families. The 7 th supplied blood types of the patient himself and one of his parents, and the 8th, only that of herself. In the 1st and 2nd families, the type of a healthy spouse proved non-secretory and that of an invalid spouse, secretory. In all instances the myotonic dystrophy and secretor (Se) genes have been handed on together. The locus of myotonic dystrophy gene was linked with that of secretorypositive gene in these two families.

(2) As the investigation was genealogically related to parents and children, all individual parents and children were studied by Chi-square test for any significant difference in the distribution between the healthy subjects and patients. There was not a significant difference in both parents (Table 1-i, p>0.75) and children (Table 1-ii, $\mathrm{p}>0.70$ ).

(3) Of the families under observation, both parents proved to belong to the secretory type in 2 families, and either of the parents, to either secretory or nonsecretory in 4 families. There was no combination of parents in which both of them had non-secretory type. As regards the distribution in children, the total number of children is shown with the number of affected children in parentheses. Expected distribution of affected children from these parent matings was also shown (Table 2). The report of Komatsu on the genealogy of the Japanese was the basis of the expected number of affected children (Komatsu, 1936). The Chi-square testing performed on the expected group and observed group did not produce a significant difference in all who were tested as well as in patients alone. This, therefore, indicates that the distribution of affected children in the present study corresponds with those in a general population. 
$I$ (E. F.)

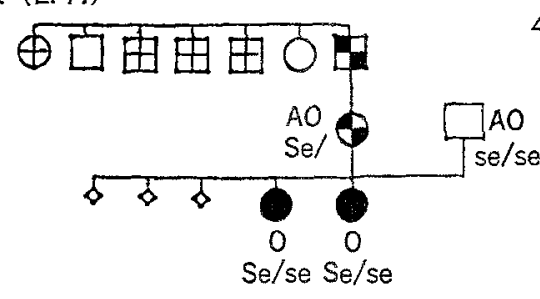

2 (H. I.)

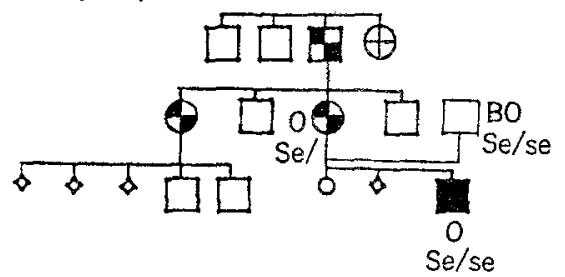

3 (Y. M.)

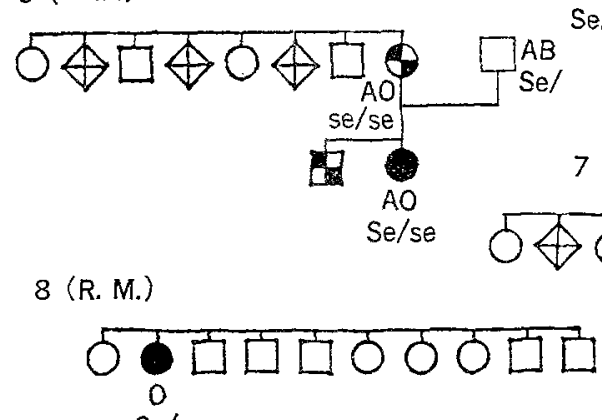

$\mathrm{Sel}$
4 (s. o.)

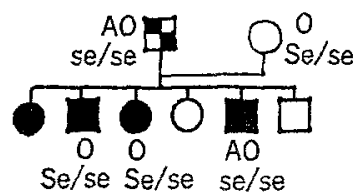

5 (M. Y.)

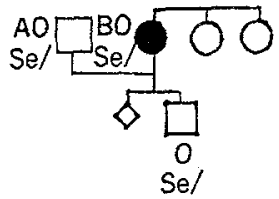

6 (K. K.)

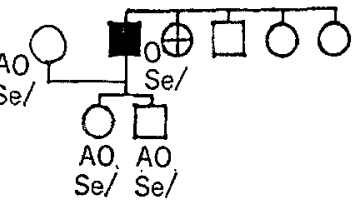

7 (T. U.)

AO
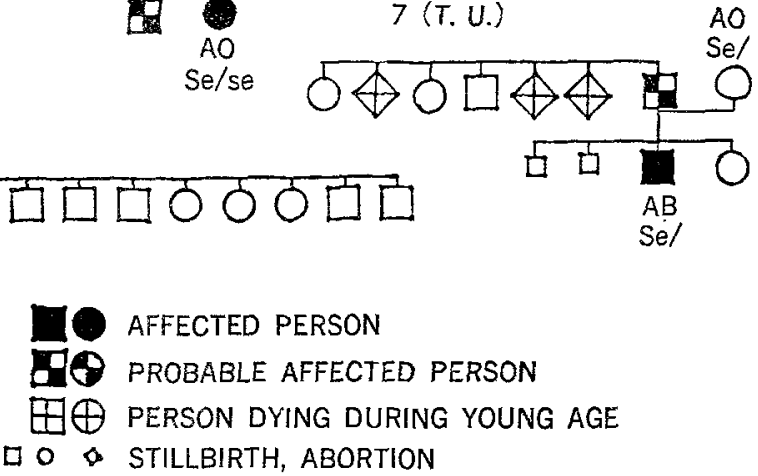

Fig. 1. Pedigree of families with myotonic dystrophy. The family pedigree shows the secretor phenotypes (Se/ ) or genotype (Se/se, se/se) of available family members. Secretor renotypes were inferred from examination of sibs, parents, or children. ABO blood type is also indicated.

\section{DISCUSSION}

The distribution of secretors and non-secretors with myotonic dystrophy in San-in district of Japan did not differ between the affected parents and a general population, and between the progenies of the former and the latter. It means that the genetic linkage between the locus for myotonic dystrophy and the $\mathrm{ABH}$-secretion locus is seen equilibrated (Weinberg, 1908).

Therefore, the patients with myotonic dystrophy in San-in district of Japan seem 
Table 1. The distribution of secretors and non-secretors between non-affected persons and patients with myotonic dystrophy.

\begin{tabular}{lcc}
\hline & Secretors & Non-secretors \\
\hline Non-affected parent & 5 & 3 \\
(Affected parent) & $(5)$ & $(1)$ \\
Non affected children & 3 & 0 \\
(Affected children) & $(7)$ & $(1)$
\end{tabular}

(i) Case of parents

\begin{tabular}{lccc} 
& Secretors & Non-secretors & Total \\
\hline Non-affected & 5 & 3 & 8 \\
Affected & 5 & 1 & 6 \\
Total & 10 & 4 & 14 \\
\hline
\end{tabular}

$\chi^{2}=0.066,0.75<\mathrm{p}<0.80$.

(ii) Case of children

\begin{tabular}{lccc}
\hline & Secretors & Non-secretors & Total \\
\hline Non-affected & 3 & 0 & 3 \\
Affected & 7 & 1 & 8 \\
Total & 10 & 1 & 11 \\
\hline
\end{tabular}

$\chi^{2}=0.104,0.70<\mathrm{p}<0.75$

Table 2. Observed mating types, and observed and expected progeny distribution of secretors and non-secretors (Chi-square test performed).

\begin{tabular}{|c|c|c|c|c|c|c|c|}
\hline \multirow{2}{*}{$\begin{array}{l}\text { Mating } \\
\text { types }\end{array}$} & \multirow{2}{*}{$\begin{array}{l}\text { Number of } \\
\text { families }\end{array}$} & \multicolumn{2}{|c|}{ Progeny types } & \multirow{2}{*}{ Total } & \multirow{2}{*}{$\gamma^{2}$} & \multirow{2}{*}{ d.f. } & \multirow{2}{*}{$\mathrm{p}$} \\
\hline & & $S$ & NS & & & & \\
\hline $\mathbf{S} \times \mathbf{S}$ & 2 & $\begin{array}{l}3(0)^{2} \\
2.66^{b}\end{array}$ & $\begin{array}{l}0(0)^{\mathrm{a}} \\
0.34^{\mathrm{b}}\end{array}$ & $3(0)$ & $0.386(0)$ & $1(0)$ & $>0.50$ \\
\hline $\mathrm{S} \times \mathrm{NS}$ & 4 & $\begin{array}{l}6(6)^{\mathrm{a}} \\
4.64 \mathrm{~b}\end{array}$ & $\begin{array}{l}1(1)^{\mathrm{a}} \\
2.36^{\mathrm{b}}\end{array}$ & $7(7)$ & $1.19(1.19)$ & $1(0)$ & $>0.20$ \\
\hline Total & 6 & $9(6)$ & $1(1)$ & $10(7)$ & $1.576(1.19)$ & $2(0)$ & $>0.30(>0.20)$ \\
\hline
\end{tabular}

Figures within parentheses indicate the case of affected child (children). a The total number of child (children), with the number of affected child (children) within parentheses. b The expected number of child (children) from these parents. S, secretor; NS, non-secretor.

to have originated very long ago, and after passage of many generations such a population as adaptable to the Hardy-Weinberg Law has been formed upto the time of this survey.

Jpn. J. Human Genet. 
The investigation in San-in district revealed at least 9 families with patients with myotonic dystrophy through 3 successive generations.

There was no confliction with the linkage between the myotonic dystrophy gene and secretor gene in each pedigree having successive offsprings over generations.

The most valuable information can be obtained in the families (No. 1 and 2 in Fig. 1) where the affected parent is a secretor, married to a non-secretor. If, in this affected parent, the myotonic dystrophy allele is on the same homologue as the secretor allele, and the clinically normal offspring is secretor negative, there would be a $100 \%$ reliable prediction of normality for that offspring, in the absence of crossing-over.

Even though this approach is not applicable to most families and although the process of genetic recombination complicates the analysis, in individual cases the use of linkage may be very helpful for preclinical detection, prenatal prediction, and more precise genetic counseling.

\section{REFERENCES}

Grubb, R. 1948. Correlation between Lewis blood group and secretor character in man. Nature, Lond. 162: 933.

Harper, P.S., Bias, W.B., Hutchinson, J.R., and McKusick, V.A. 1971. ABH sector status of the fetus: A genetic marker identifiable by amniocentesis. J. Med. Genet. 8: 438-440.

Harper, P.S., Rivas, M.L., Bias, W.B.M., Hutchinson, J.R., Dyken, P.R., and McKusick, V.A. 1972. Genetic linkage confirmed between the locus for myotonic dystrophy and the ABH secretion and Lutheran blood group loci. Am. J. Hum. Genet. 24: 310-316.

Komatsu, Y. 1936. A study on probability relating to inheritance of blood group. J. Criminol. (in Japanese) 10:594-600.

Nei, M. 1979. Proportion of informative families for genetic counseling with linked marker genes. Jpn. J. Human Genet. 24: 131-142.

Renwick, J.H., Bundey, S.E., Ferguson-Smith, M.A., and Izatt, M.M. 1971. Confirmation of linkage of the loci for myotonic dystrophy and ABH secretion. J. Med. Genet. 8: 407-416.

Weinberg, W. 1908. Über den Nachweis der Vererbung beim Menschen. Jahreshefte Verein . vaterl. Naturk, in Württemberg. 64: 368-382. 